\title{
ASSÉDIO MORAL NAS MICROS E PEQUENAS EMPRESAS: UMA VERDADE QUE
}

\author{
NÃO APARECE
}

\author{
Ana Litilha Fleck ${ }^{1}$ \\ Rosiane Oswald Flach² \\ Recebido em: 30 set. 2019 \\ Aceito em: 10 jun. 2020
}

\begin{abstract}
Como citar este artigo: FLECK, A.; OSWALD FLACH, R. ASSÉDIO MORAL NAS MICROS E PEQUENAS EMPRESAS: UMA VERDADE QUE NÃO APARECE. Revista Visão: Gestão

Organizacional, v.9, n.1, p.52-70. DOI: https://doi.org/10.33362/visao.v9i1.2135.
\end{abstract}

Resumo: Este estudo tem como objetivo identificar o assédio moral nas micro e pequenas empresas e sua ligação com o gênero. Realizou-se uma pesquisa quantitativa e descritiva, utilizando como estratégia de estudo de campo a aplicação de um questionário com 155 profissionais que atuam em micro e pequenas empresas. A produção e análise dos dados ocorreram por meio de estatística descritiva. Os achados demonstram que o ato de assédio moral ocorre com ambos os gêneros, mas possui uma intensidade maior com as mulheres, sendo reconhecido como uma violência. Desta forma, repercutem seus efeitos no desenvolvimento do trabalho realizado e na vida das vítimas, os quais por motivos de medo e receio de perder o trabalho não efetuam a denúncia. Este trabalho contribui academicamente ao suprir a lacuna de pesquisas sobre Assédio Moral e suas consequências nas vítimas e pode auxiliar os responsáveis pela gestão das empresas em compreender melhor quais ambientes são mais favoráveis a este tipo de violência e buscar ferramentas de gestão para inibir este fenômeno destruir do ambiente de trabalho.

Palavras-Chave: Assédio Moral. Micros e Pequenas Empresas. Gênero.

\section{PSYCHOLOGICAL HARASSMENT IN MICRO AND SMALL BUSINESSES: A TRUTH THAT DOESN'T APPEAR}

Abstract: This study has the objective to investigate psychological harassment in micro and small businesses and their connection with gender. A quantitative and descriptive research was done, using as a field study strategy the application of a questionnaire with 155 professionals working in micro and small companies. The production and analysis of the data occurred through descriptive statistics. The results demonstrate that the act of psychological harassment occurs with both genders, but has a greater intensity with women, being recognized as violence. Therefore, it affects the development of work and the victims lives, who, for reasons of fear and scared to lose their jobs, do not file a

\footnotetext{
1 Egressa do Curso de Administração pelo Centro Universitário Fai (UCEFF). E-mail: premium.itapiranga@uceff.edu.br.

2 Graduada em Administração. Mestre em Administração pela Universidade do Vale do Itajaí (2010). Centro Universitário Fai (UCEFF). E-mail: rosiane.oswald@bol.com.br.
} 
complaint. This work contributes academically by filling the research gap about Psychological Harassment and its consequences in the victims and can help those in charge of the companies management to better understand which environments are more favorable to this type of violence and seek management tools to inhibit this phenomenon from the work environment.

Keywords: Psychological Harassment. Micro and Small Businesses. Genre.

\section{INTRODUÇÃO}

O ambiente de trabalho, nos últimos anos, tem sido um local de violência e humilhações, e tal ato hostil era desconhecido ou simplesmente ignorado. O assédio moral tem sido uma temática que vem ganhando destaque no meio organizacional, assim como também em estudos e pesquisas científicas. Essa notoriedade deu-se por conta do significativo aumento na quantidade de casos com denúncias formais, o que demonstrou ser um grande problema e que precisa ser enfrentado de modo mais eficaz.

De acordo com a autora francesa Hirigoyen (2000), o ato de assédio moral no ambiente laboral pode ser reconhecido como qualquer comportamento impróprio sendo ele com palavras, gestos, conduta e atitudes, que sejam provocados por várias vezes, desmerecendo a dignidade ou a integridade física e psíquica da vítima, podendo ocasionar danos no ambiente de trabalho e ameaças ao seu emprego.

Inicialmente, percebido como algo inofensivo as vítimas não se sentem ofendidas com determinadas afrontas considerando como uma brincadeira, o que com o passar do tempo passa se tornar algo rotineiro e a vítima sente-se constrangido posto em situação de inferioridade, assim o assédio moral propaga-se de forma inclemente (RIBEIRO; MANCINI NETO, 2003).

É relevante destacar que entre o período de 2007 e agosto de 2017, foram registradas em 229 empresas, 168.965 denúncias de assédio no Ministério Público do Trabalho, das quais $(43,1 \%)$ foram na área de relacionamento interpessoal, e $(25,66 \%)$ estão relacionadas as práticas consideradas abusivas, ligadas ao assédio moral, assédio sexual, agressão física, discriminação e preconceito (ALMEIDA; CAVALCANTI; BATISTA, 2018).

A partir das evidências, surge o questionamento que orienta a realização deste trabalho: identificar o assédio moral nas micros e pequenas empresas? Para responder à questão central, o objetivo do presente trabalho consiste em identificar o assédio moral nas micros e pequenas empresas e sua ligação com o gênero. Evidencia-se a necessidade de estudos na área organizacional das empresas para melhor compreensão e identificação dos fatos ocorridos no ambiente de laboral, sendo eles ligados as atitudes abusivas e comportamentos inadequados entre os participantes do mesmo.

Assim, a primeira contribuição deste estudo se encontra em identificar as relações 
estabelecidas no ambiente de trabalho que geram assédio moral, além de discutir como os profissionais se manifestam ao passar pela situação. Neste estudo, o modelo de negócio (micro e pequenas empresas) ganha relevância ao se tornar junto com o assédio moral a variável de interesse.

Para os gestores, identificar os tipos de comportamento mais propensos à ocorrência do assédio moral pode ser uma importante informação no processo de gestão, uma vez que muitos dos problemas existentes no meio organizacional estão relacionados ao abuso de poder, aos níveis excessivos de competição, disputa e preconceito de gênero no que diz respeito à ocupação de cargos, ao que tange à saúde física e psíquica, as perdas corporativas com a diminuição da produtividade, o afastamento do funcionário por motivos de doenças reciprocas do assédio, o que acaba gerando custos adicionais para as empresas.

Ademais, espera-se ampliar o conhecimento e colaborar com a literatura acadêmica, num processo cooperativo para a propagação do saber científico na área de Administração e afins. Assim, este estudo parte da visão de Campos e Rueda (2016), estes que destacam que as pesquisas sobre assédio moral não se esgotaram e precisam de novas investigações.

Este artigo está estruturado da seguinte forma: inicia-se com esta introdução, seguida do referencial teórico, onde são discutidos os conceitos de assédio moral e as pesquisas recentes sobre o tema. Após é apresentada a metodologia da pesquisa, e por fim, se apresentarem os dados e resultados seguidos da referida discussão e das considerações finais.

\section{O ASSÉDIO MORAL NAS EMPRESAS}

O assédio moral tem sido um problema presente no ambiente de trabalho, não se constituindo de uma situação nova nas relações laborais, mas que nos últimos anos obteve um aumento significativo em diferentes ambientes de trabalho e categorias profissionais, sendo uma forma de violência que nem sempre é percebida com tal. Somente na década de 1990, o termo assédio moral passou a ser alvo de estudos, considerando o fato de ser reconhecido como um fenômeno destruidor do ambiente laboral nas empresas (HIRIGOYEN, 2000).

Nesse sentido, Freitas (2001) avaliava o assédio moral como sendo uma prática a qual leva à fragilidade e neutralização da vítima em seu ambiente de trabalho. Inicialmente, o ato de assédio moral é entendido com algo inofensivo e de forma desleal se propaga. As vítimas, de início, não se sentem ofendidas e humilhadas com as afrontas e acabam por levar na brincadeira, mas com o passar do tempo torna-se algo rotineiro e o indivíduo sente-se perseguido posto em situação de inferioridade (RIBEIRO; MANCINI NETO, 2003).

Os autores Freitas, Heloani e Barreto (2008) destacam o aspecto da frequência das práticas, ao retratarem o ato como uma conduta abusiva, de modo intencional, humilhante, frequente e repetida que diminui a vítima, que constrange e desqualifica, a qual tem o intuito de destruir psicologicamente o indivíduo. Uma das questões que favorecem a ocorrência do 
assédio moral no ambiente de trabalho é a não existência de regras internas nas empresas, nem para os comportamentos nem para os métodos, e o poder do líder não possui limites, quando é realizado um pedido aos subordinados (HIRIGOYEN, 2008).

Os danos sociais, referentes ao assédio moral, são inúmeros, uma vez que acaba por afetar todas as esferas de sua vida, incluindo a família, o seu círculo de amizade e convívio social, e por consequência a vítima passa a abandonar seus compromissos e passa a adotar uma postura de ausência sob as pessoas mais próximas, causando perdas de amizades e problemas conjugais (FREIRE, 2009). O assédio moral possui várias faces negativas, como na diminuição da produtividade, no aumento do absenteísmo e turnover, sucedidos dos danos psicológicos causados pela violência. Em uma empresa, o ambiente de trabalho é composto por indivíduos que lutam por seus interesses e, nesse ponto, as empresas possuem uma parcela de culpa, pelo fato de instigar essa tal luta, sob o argumento de que desenvolver competição e audácia é considerado como algo benéfico (MAÑAS, 2009).

Esse novo perfil, individualista e ambicioso, o qual passou a ser exigido do trabalhador contribui para o desenvolvimento de um comportamento agressivo, posto assim em uma situação de impasse, onde de um lado cria-se a necessidade de ser um indivíduo mais competitivo, qualificado, capaz, criativo e multifuncional; e de outro, sabe que não estar preparado para enfrentar a nova realidade de mercado pode representar a perda do emprego (MARTININGO FILHO; SIQUEIRA, 2008).

Hirigoyen (2008) destaca que a idade média das vítimas de assédio moral é de acima de 48 anos de idade, os quais são julgados pelos agressores como menos produtivos e não oferecem um nível satisfatório suficiente de adaptações no contexto organizacional. $O$ ato de assédio moral prevalece com um maior índice no gênero feminino sendo (70\%), enquanto o gênero masculino representa (30\%) das violências sofridas, sendo que está taxa percentual pode variar de acordo com o contexto sociocultural; considerando que em alguns países os homens creem que cada mulher inserida no mercado de trabalho é responsável pelo desemprego de um homem.

Teixeira, Reis e Santos (2013) ressaltam que o meio laboral tem sido apontado como palco para as mais diversas formas de violência, desobedecendo aos direitos humanos, assim como suas características e diferenças, tornando uma disputa interna composta por aversão e carência de empatia pelo outro. De acordo com os princípios e direitos dos cidadãos expostos na Constituição Federal, eles firmam proteção ao trabalhador, aos valores sociais do trabalho, à igualdade de direitos e também de suas obrigações nos distintos gêneros, homens e mulheres, à sua livre iniciativa e à defesa da violência da honra e imagem do indivíduo (BOBROFF; MARTINS, 2013).

Deste modo, a conduta violenta de assédio rompe as expectativas e oportunidades criadas em relação ao trabalho realizado pela vítima, deixando-a sob alvo do medo, ainda 
comprometendo as possíveis vantagens competitivas da empresa em decorrência da vivência dos indivíduos em um ambiente adverso do que o esperado (VALADÃO JUNIOR; MENDONÇA, 2015). Neste sentido, no subtítulo imediato, serão apresentadas algumas pesquisas recentes que referenciam o ato de assédio moral no ambiente de trabalho, especificadamente nas empresas.

\section{PESQUISAS RECENTES SOBRE O ASSÉDIO MORAL}

Embora o tema em estudo seja considerado relativamente recente, foram selecionados alguns estudos que apresentam a necessidade do tema se manter em agenda de pesquisa. Inicialmente, Silva; Nakata (2016) realizaram um estudo cujo objetivo principal foi compreender os motivos pelos quais os indivíduos que sofrem a violência do assédio moral permanecem na organização. Os autores consideram que o assédio moral é um fenômeno cultural, a qual é formada por conjecturas criadas e retratadas pelas pessoas, no qual o seu comportamento está ligado aos seus valores e crenças bem como em sua atuação social.

A pesquisa se deu por meio de um estudo descritivo e de natureza quantitativa, no qual o instrumento de coleta de dados foi um questionário on-line com (16) questões, sendo que os pesquisadores obtiveram (100) respondentes válidos. A amostra se limitou em entrevistar pessoas que já possuíram alguma experiência de trabalho, sendo ela remunerada ou não, mas que se compreende como qualquer atividade de trabalho na qual carecia de disponibilidade física, mental e temporal, e que o mesmo já tivesse sofrido assédio moral (SILVA; NAKATA, 2016).

Conforme Silva e Nakata (2016), as vítimas caracterizaram o ato de assédio moral com condutas e comportamentos que buscam desestruturar a vítima, de modo físico e psíquico. Ainda, a pesquisa possibilitou identificar que as vítimas permanecem no mesmo ambiente de trabalho por motivos financeiros, pois um indivíduo procurar uma atividade remunerada por conta do fim econômico para sua sobrevivência e manutenção. Os autores destacam a importância de desenvolver outros estudos que busque compreender melhor e aprofundar o conhecimento sobre os motivos os quais levam a permanência das vítimas no mesmo local de trabalho.

Corroborando os autores Marazzo et. al. (2017) desenvolveram um estudo no qual buscaram conhecer mais este fenômeno devido as inúmeras denúncias de assédio moral e outros tipos de atos de violência no ambiente de trabalho, tendo como objetivo geral propor ações preventivas para coibir a assédio moral no ambiente organizacional. A pesquisa foi de caráter exploratório e qualitativo, realizada com (30) especialistas, os quais responderam um questionário com (10) questões, usando (2) escalas e (1) questão aberta, deste modo pode-se observar que os atos de assédio moral, conforme listados no questionário, ocorreram com uma certa frequência no ambiente laboral, o que demonstrou um impacto significativo no meio 
organizacional.

O estudo destacou que o número de denúncias nos últimos anos vem crescendo junto a Justiça do Trabalho, as quais são registradas pelos sindicatos e pela própria vítima, onde que por muitas vezes foi necessário a intervenção da Procuradoria Regional do Trabalho que promoveu a proteção do trabalhador. (MARAZZO et. al., 2017)

Agregando valor, Mendonça, Santos e Paula (2018) realizaram um artigo cujo foco central da pesquisa foi identificar as preferencias metodológicas no desenvolvimento de estudos, bem como elucidar a origem institucional dos autores, as obras mais utilizadas e os campos para novos trabalhos. Para o desenvolvimento do estudo, os dados coletados tiveram como base de informação os periódicos brasileiros do período de 2001 a outubro de 2016, os quais referenciaram as áreas de Administração e Psicologia Social e do Trabalho, também de canais do Encontro Nacional da Associação Nacional de Pós-Graduação e Pesquisa em Administração (EnAnpad).

A pesquisa desenvolvida elucidou a origem institucional dos autores, as obras mais utilizadas e as lacunas para novos estudos. Observou-se que as publicações nacionais sobre o tema em estudo, vêm destacando-se o que mostra uma média de três trabalhos por ano, e que o período que se obteve publicações foram entre 2008 e 2013, representando (74\%) dos trabalhos analisados, foram investigadas (28) revistas onde (12) delas publicaram artigos referentes ao assédio moral no trabalho, das quais (7) possuem escopo na área de Administração e as demais na área de Psicologia, destacando as revistas ERA, Cadernos EBAPE e Psicologia \& Sociedade (MENDONÇA; SANTOS; PAULA, 2018).

Culminando esse pressuposto, Silva, Castro e Dos-Santos (2018) desenvolveram um estudo que buscou investigar a relação entre cultura organizacional, o assédio moral e a satisfação no trabalho. A aplicação ocorreu com trabalhadores de empresas das cidades de Salvador e Feira de Santana, no estado da Bahia, no qual obtiveram (912) questionários respondidos.

Os resultados indicam relações existentes entre os conceitos, haja vista o fato de que as culturas clã e adocrática demonstraram obter uma ligação contrária entres seus membros e o ato do assédio moral, em que ambas as culturas se inclinam para reprimir a existência do assédio moral. Já em contrapartida, a cultura de mercado revelou-se estar associada ao ato de assédio moral e que uma favorece o surgimento da outra. Na comparação da cultura com a satisfação, considerando as culturas hierárquicas e adocrática, demonstraram estar, de modo positivo, associadas com a satisfação, e de modo contrário a cultura de mercado mostrou-se sinais contrários referentes a satisfação. Na análise de estudo a cultura clã não apresentou relevância estatística. E, por fim, ressalta o efeito regulador do assédio moral na atuação da cultura acerca da satisfação, o que demonstra ser muito importante (SILVA; CASTRO; DOSSANTOS, 2018). 
Os estudos recentes procuraram elucidar alguns temas acerca do assédio moral dos últimos anos, nos quais os autores buscaram em suas obras conhecer melhor este fenômeno de violência que atinge o ambiente organizacional, bem como identificar as preferencias metodológicas no desenvolvimento de estudos e origem institucionais dos autores, e ainda o entendimento da relação entra cultura organizacional, assédio moral e a satisfação no trabalho. O tópico seguinte apresenta as metodologias utilizadas para o desenvolvimento deste presente estudo.

\section{PROCEDIMENTOS METODOLÓGICOS}

O presente estudo teve como objetivo central identificar o assédio moral nas micros e pequenas empresas e sua ligação com o gênero, por meio do desenvolvimento e aplicação de um questionário estruturado.

O mesmo se caracteriza como sendo uma pesquisa quantitativa com base descritiva, coordenado por uma pesquisa teórico-empírica, por meio da produção e análise de conhecimentos, dado que, afora a coleta de dados secundários em artigos e livros, a pesquisa também envolve fontes primárias, ou seja, através da coleta de dados por meio da pesquisa de campo. O estudo se configura como sendo quantitativo, pois tem o desígnio de quantificar as informações retidas mediante técnicas estatísticas. Portanto, através de médias, percentuais etc., o estudo procura descobrir as relevantes características necessárias (RICHARDSON, 2011).

Para o desenvolvimento da coleta de dados foi empregado o método de pesquisa survey, considerando que a pesquisa é de cunho teórico-empírica e busca reunir dados primários. Este método de pesquisa utiliza-se de uma forma direta para interrogar as pessoas, com o intuito de descobrir informações de um grupo considerável de indivíduos referente ao problema a ser estudado, por meio da análise quantitativa, alcançando os resultados desejados sendo correspondentes às informações recolhidas (GIL, 2008).

Antecedente à elaboração da pesquisa, o presente estudo foi submetido à aceitação do Comitê de Ética em Pesquisa. Para a coleta de dados foi utilizado um questionário o qual é baseado na obra de Felipe (2016), denominada "Assédio Moral contra as mulheres: um estudo com técnicas administrativas da Universidade do Estado do Rio Grande do Norte", no qual a autora busca compreender as categorias de divisão sexual do trabalho, relações patriarcais de gênero e assédio moral em sua ligação com as mudanças procedentes da reorganização produtiva, o trabalho, assim como também contribuir com dados para a realização da análise dos impactos do assédio moral na vida das servidoras técnico-administrativas de nível médio da UERN.

O questionário foi constituído por (48) questões, de respostas abertas e fechadas, as mesmas foram desenvolvidas em seis seções, em que inicialmente descreveu-se o instrumento 
de coleta de dados com o questionamento de optar pela participação do mesmo ou não. A segunda seção compreende (17) questões relativas à caracterização do perfil do respondente; a terceira seção é composta por (11) questões à qual refere-se ao trabalho na vida dos(a) entrevistados(a); a quarta seção compreende (12) questões as quais evidenciam as expressões de violência na esfera do trabalho; a quinta seção é composta por (4) questões que buscam destacar as reações diante do assédio moral vivenciado que aborda; e pôr fim a sexta e última seção é composta por (3) questões que refere-se aos mecanismos de enfrentamento ao assédio moral na esfera de trabalho.

Por conseguinte, o desenvolvimento do estudo deu-se início no dia 26 de julho de 2018, e a coleta de informações iniciou-se no dia 08 de setembro do mesmo ano com compartilhamento do questionário e encerou-se 28 dias após. Tal pesquisa buscou compreender participantes que possuíssem vínculo empregatício ou que já possuíram, de modo que concerne à sua participação. Após concluir esta etapa, a seção seguinte exibirá a análise e discussão dos resultados descobertos durante a pesquisa de campo.

A amostra corresponde a 155 profissionais que atuam ou atuaram em micro e pequenas empresas. Os respondentes tiveram acesso à pesquisa por meio de um link online, o qual foi viabilizado nas redes sociais e encaminhado por e-mails, o mesmo foi estruturado no Google Drive, o qual foi utilizado como ferramenta para a tabulação dos dados. O desenvolvimento da análise dos dados aconteceu por meio de estatística descritiva, analisando-se os resultados por frequência, os níveis de percentual, bem como a média e desvio padrão.

\section{ANÁLISE DOS RESULTADOS}

A análise de resultados foi desenvolvida em duas etapas. A primeira, busca descrever o perfil do participante e a relação laboral através de dados primários, a segunda etapa buscar relatar o assédio moral perante a visão e o conhecimento dos mesmos referentes ao tema.

\section{ANÁLISES DESCRITIVAS DO CONTEXTO DO TRABALHO}

Para o desenvolvimento do estudo buscou-se atingir um número mínimo de participantes, sendo (150) respondentes, com a divulgação da pesquisa nas mídias sociais e envio individual, por meio do facebook, e-mail e grupos de aplicativos, foi possível obter uma amostra de (155) respondentes válidos. A Tabela 1 apresenta a descrição do perfil do respondente do questionário: 
Tabela 1. Descrição do perfil do respondente.

\begin{tabular}{|c|c|c|c|c|}
\hline \multicolumn{5}{|c|}{ Definição enquanto raça/cor/etnia } \\
\hline Negra & Parda & Branca & Indígena & Outra \\
\hline $2(1,3 \%)$ & $10(6,5 \%)$ & $143(92,3 \%)$ & 0 & 0 \\
\hline \multicolumn{5}{|c|}{ Definição enquanto orientação sexual } \\
\hline Heterossexual & Homossexual & Lésbica & Bissexual & $\mathrm{SN} / \mathrm{NR}$ \\
\hline $152(98,1 \%)$ & $2(1,3 \%)$ & $1(0,6 \%)$ & 0 & 0 \\
\hline \multicolumn{5}{|c|}{ Região geográfica de sua origem } \\
\hline Nordeste & Sul & Norte & Centro Oeste & Sudeste \\
\hline $8(5,2 \%)$ & $142(91,6 \%)$ & $3(1,9 \%)$ & $2(1,3 \%)$ & 0 \\
\hline \multicolumn{5}{|l|}{ Estado civil } \\
\hline Solteiro & Casado & Divorciado & NS/NR & Viúvo(a) \\
\hline $94(60,6 \%)$ & $56(36,1 \%)$ & $3(1,9 \%)$ & $2(1,3 \%)$ & 0 \\
\hline \multicolumn{5}{|l|}{ Tem filhos(as) } \\
\hline Não & Sim & & & \\
\hline $106(68,4 \%)$ & $49(31,6 \%)$ & & & \\
\hline \multicolumn{5}{|c|}{ Reside em domicílio } \\
\hline Próprio & Alugado & Financiado & Cedido & Outros \\
\hline $92(59,4 \%)$ & $34(21,9 \%)$ & $16(10,3 \%)$ & $6(3,9 \%)$ & $7(4,5 \%)$ \\
\hline
\end{tabular}

Fonte: Dados da pesquisa.

Com base nas informações registradas é possível destacar que (92,3\%) dos respondentes se declaram brancos, enquanto orientação sexual, $(98,1 \%)$ declaram-se heterossexual e $(91,6 \%)$ reside na região sul do país. Já no que tange à formação profissional, foi possível identificar que $(47,1 \%)$ possuem Ensino Superior Incompleto e $(36,8 \%)$ Ensino Superior Completo, e $(92,3 \%)$ dos participantes estão trabalhando no momento. Destaca-se que os respondentes iniciaram no mercado de trabalho através de indicações, via currículo vitae, concurso/seleção pública, por convite, por meio de estágio, e alguns como autônomos. A Tabela 02 apresenta as funções e salários do público investigado:

Tabela 2. Descrição horas, funções e salários.

\begin{tabular}{|c|c|c|c|c|}
\hline \multicolumn{5}{|c|}{ Carga horária diária de trabalho } \\
\hline 4 horas & 6 horas & 8 horas & Mais de 8 horas & \\
\hline $10(6,5 \%)$ & $11(7,1 \%)$ & $82(52,9 \%)$ & $52(33,5 \%)$ & \\
\hline \multicolumn{5}{|c|}{ Função desenvolvida } \\
\hline Operacional & Auxiliar Adm. & Gestor & Outra & \\
\hline $24(15,5 \%)$ & $38(24,5 \%)$ & $30(19,4 \%)$ & $63(40,6 \%)$ & \\
\hline \multicolumn{5}{|l|}{ Faixa salarial } \\
\hline $\begin{array}{l}\text { de } 954,00 \text { a } \\
1.500,00\end{array}$ & $\begin{array}{l}\text { de } 1.556,89 \text { a } \\
2.500,00\end{array}$ & $\begin{array}{l}\text { de } 2.500,00 \text { a } \\
3.500,00\end{array}$ & $\begin{array}{l}\text { de } 3.500,00 \text { a } \\
5.000,00\end{array}$ & acima de $5.000,00$ \\
\hline $58(37,4 \%)$ & $39(25,2 \%)$ & $22(14,2 \%)$ & $14(9 \%)$ & $22(14,2 \%)$ \\
\hline
\end{tabular}

Fonte: Dados da pesquisa. 
Os resultados indicam que grande parte dos respondentes (52,9\%) trabalham 8 horas por dia; no que tange à faixa salarial, $(37,4 \%)$ recebem salários que variam de $R \$ 954,00$ a $\mathrm{R} \$ 1.500,00$, e na descrição de funções laborais desenvolvidas pelos mesmos 40,6\% (63) responderam outra classificação para descrever sua função laboral, outros 24,5\% (38) exercem a função de auxiliar administrativo, 19,4\% (30) ocupam a função de gestor e 15,5\% (24) atuam na sessão operacional.

Entre os entrevistados, $(82,6 \%)$ possuem mais de uma renda salarial no grupo familiar, porém para $(16,8 \%)$ esta é a única renda para manter as despesas familiares, das quais $(25,8 \%)$ possuem uma pessoa como dependente, $(21,9 \%)$ possuem duas pessoas como dependentes, $(14,2 \%)$ possuem três pessoas como dependentes e $(4,5 \%)$ possuem quatro pessoas como dependentes. Ficou evidenciado que grande parte dos respondentes iniciou a vida laboral na adolescência, entre 18 (16,8\%) e 16 (14,8\%) anos de idade. Sendo interessante destacar que $(25,8 \%)$ permanecem no mesmo local e $(74,2 \%)$ já mudaram de local de trabalho, dos quais $(74,2 \%)$ tiveram seus direitos trabalhistas assegurados e $(22,6 \%)$ não tiveram. Destaca-se que para $(83,9 \%)$ o trabalho é muito importante em suas vidas.

Na concepção dos respondentes, no que toca as relações entre homens e mulheres no ambiente laboral, (75,5\%) disseram haver igualdade de tratamento, já (13,5\%) afirmaram haver desigualdade de relações e (11\%) nunca refletiram sobre esta questão, e os mesmos justificaram dizendo que existe a desigualdade salarial, bem como o tratamento com indiferença e desmerecimento da mulher, muitos dos ambientes possuem mais homens e pouca oportunidade para as mulheres. Em conformidade, alguns descrever haver parcialidade nas relações de gênero no ambiente de trabalho, e outros até o momento não presenciaram ou viram algum tipo de desigualdade de gênero nas atividades laborais.

Em relação à satisfação com o emprego atual, (84,5\%) disseram estar satisfeitos, (11\%)afirmam não estar e (4,5\%) optaram por não responder, no qual os não satisfeitos ressaltaram como principais motivos do descontentamento: salários, clima organizacional, falta de desenvolvimento de carreira, falta de reconhecimento profissional e oportunidades, desrespeito e humilhações.

Com base na satisfação dos respondentes $(76,1 \%)$ responderam não querer mudar de setor, enquanto $(16,1 \%)$ desejariam trocar de local de trabalho, tendo como motivos de troca o próprio ambiente de trabalho e o clima conturbado e acintoso, como também, a insatisfação com os níveis hierárquicos.

Ao analisar as informações, é possível compreender que muitos dos fatos de insatisfação que ocorrem no ambiente de trabalho são provenientes de problemas pertencentes ao relacionamento com colegas, a forma como as pessoas se manifestam, bem como, o reconhecimento e desenvolvimento profissional, tanto ligado à carreira como financeiramente. 
Diante disto, a satisfação pode ser entendida como sendo uma condição de caráter emocional prazeroso o qual deriva de diferentes pontos do trabalho e que pode ser influenciada pela opinião de mundo e pelos anseios, vivências e características individuais de cada trabalhador, envolvendo formas distintas de enfrentamento dos problemas e a costumeira tomada de decisões (SCHERE; PIRES; SCHWARTZ, 2009). O próximo tópico aborda uma análise dos principais questionamentos quanto o assédio moral no ambiente de trabalho.

\section{O ASSÉDIO MORAL NO AMBIENTE DE TRABALHO}

Nesta sessão busca-se descrever, com base no questionário realizado, uma análise referente as expressões de violência na esfera do trabalho e as reações dos indivíduos diante do assédio moral e os mecanismos de enfrentamentos ao ato de assédio moral no ambiente de trabalho. A Tabela 3 apresenta os dados referente ao ato de violência e assédio moral no ambiente de trabalho, conforme análise do questionário aplicado.

Tabela 3. Dados referente ao ato de violência e assédio moral no ambiente de trabalho

\begin{tabular}{|c|c|c|c|c|}
\hline \multicolumn{5}{|c|}{ Existe violência na esfera do trabalho } \\
\hline Sim & Não & NS/NR & & \\
\hline $99(63,9 \%)$ & $53(34,2 \%)$ & $3(1,9 \%)$ & & \\
\hline \multicolumn{5}{|c|}{ A violência ocorrem contra } \\
\hline Mulher & Homem & Os dois & $\begin{array}{l}\text { Mais contra ao } \\
\text { homem }\end{array}$ & $\begin{array}{l}\text { Mais contra a } \\
\text { mulher }\end{array}$ \\
\hline $15(13,4 \%)$ & $2(1,8 \%)$ & $54(48,2 \%)$ & $1(0,9 \%)$ & $40(35,7 \%)$ \\
\hline \multicolumn{5}{|c|}{ Já ouviu falar em assédio moral } \\
\hline Sim & Não & & & \\
\hline $140(90,3 \%)$ & $15(9,7 \%)$ & & & \\
\hline \multicolumn{5}{|c|}{ Homens e mulheres sofrem assédio moral de modo igual na esfera de trabalho } \\
\hline Sim & Não & & & \\
\hline $68(43,9 \%)$ & $87(56,1 \%)$ & & & \\
\hline
\end{tabular}

Fonte: Dados da pesquisa.

A grande maioria dos respondentes $(63,9 \%)$ destacaram a existência do ato de violência dentro do local de trabalho, e que ela pode ocorrer tanto para ambos os gêneros, sendo que para (48,2\%) ocorre com mais assiduidade contra as mulheres e 35,7\% para com homens. Quanto ao conhecimento do termo assédio moral, (90,3\%) dos respondentes já ouviram falar no tema e $(9,7 \%)$ afirmam não conhecer, em que mais da metade $(56,1 \%)$ reconhecem haver diferença entre os gêneros e o nível de violência praticado. O Quadro 1, apresenta as principais causas e razões pelas quais ocorrem a violência do assédio moral no ambiente de trabalho nas empresas, em conformidade com a análise das questões de respostas abertas do questionário. 
Quadro 1. Caracterização do assédio moral de ambos os gêneros

\begin{tabular}{|l|l|}
\hline \multirow{5}{*}{ Gênero } & Caracterização \\
\hline \multirow{5}{*}{ Feminino } & Por ser frágil e vulnerável \\
\cline { 2 - 2 } & Físico e postura \\
\cline { 2 - 2 } & Falta de capacidade laboral \\
\cline { 2 - 2 } & Por serem mais cobradas e criticadas \\
\cline { 2 - 2 } & Desqualificação da sua capacidade \\
\cline { 2 - 2 } & Vítima de machismo constante \\
\cline { 2 - 2 } & Desigualdade de cargos e salários \\
\hline \multirow{4}{*}{ Masculino } & \\
\hline & Pressões diárias \\
\cline { 2 - 2 } & Cobrança em demasia \\
\cline { 2 - 2 } & Abuso de poder \\
\hline
\end{tabular}

Fonte: Dados da pesquisa.

Conforme Rui Neto (2008), com a crescente evolução da profissional mulher no mercado de trabalho e o espaço que vem adquirindo no decurso dos anos, mostra uma significante melhoria da participação feminina no ambiente laboral, porem está inserção não ocorreu de fato de uma maneira justa e igualitária. Devido ao histórico tradicional em que os homens ocupavam a atividades laborais e as mulheres as funções domésticas, houve uma ruptura de barreira a ser conquistada, sendo o pontapé inicial para que as mulheres pudessem alcançar seu espaço no atual ambiente econômica e social, a partir disto as implicações ainda constitui num contexto contemporâneo, o que causou as mulheres diferenciações laborais em comparação aos homens.

Os participantes relatam que o assédio pode atacar pontos distintos em homens e mulheres, sendo de acordo com o objetivo do agressor, e que - por muitas vezes - esta pressão pode estar atrelada ao cargo e não ao gênero, um fato que depende tanto do gestor bem como do funcionário, e como um pedido de ajuda sugerem a disponibilidade e utilização de ferramentas para neutralizar estes atos de humilhação e abuso.

Normalmente a vítima é provida de um nível considerável de responsabilidade acima da média, possui um grau de conhecimento superior aos demais, disposta de uma grande autoestima e, o mais interessante, ela acredita piamente nas pessoas que a cercam, com total confiança. É possível apontar como sendo os principais perfis para as vítimas de assédio moral, os trabalhadores que possuem mais de 35 anos; os indivíduos com salários muito altos; os honestos, escrupulosos e saudáveis; extremamente dedicados ao trabalho; os que não se deixam subjugar e curvar-se ao autoritarismo; sendo mais competente que o agressor; portadores de algum tipo de deficiência; os homens que estão inseridos em um grupo de mulheres; as mulheres em um grupo de homens; aqueles que possuem uma crença religiosa 
ou orientação sexual diferente a do assediador (TARCITANO; GUIMARÃES, 2004).

Já em relação ao conhecimento sobre o assédio moral, 46,4\% responderam ser uma violência no espaço de trabalho, enquanto $(29,3 \%)$ responderam ser uma forma específica de relações desiguais de gênero o espaço laboral, outros $(18,6 \%)$ destacaram ser uma forma de terror no espaço de trabalho, e os demais $(5,7 \%)$ reconhecem ser algo que faz parte do dia a dia do profissional. A seguir a Tabela 4 apresentará dados relativos ao assédio moral, em conformidade com os resultados da pesquisa.

Tabela 4. Dados ligados ao assédio moral.

\begin{tabular}{|c|c|c|c|c|}
\hline \multicolumn{5}{|c|}{ Já vivenciou/vivencia alguma situação de assédio moral no ambiente de trabalho? } \\
\hline $\operatorname{sim}$ & Não & NS/NR. & & \\
\hline $54(34,8 \%)$ & $98(63,2 \%)$ & $3(1,9 \%)$ & & \\
\hline \multicolumn{5}{|c|}{ Caso afirmativo, foi potencializado pelo que? } \\
\hline $\begin{array}{l}\text { Sua capacidade } \\
\text { intelectual }\end{array}$ & $\begin{array}{l}\text { Sua indisponibilidade de } \\
\text { trabalho em outros } \\
\text { horários }\end{array}$ & Sua aparência & $\begin{array}{l}\text { Sua orientação } \\
\text { sexual }\end{array}$ & Outro \\
\hline $18(28,6 \%)$ & $18(28,6 \%)$ & $9(14,3 \%)$ & $9(14,3 \%)$ & $9(14,3 \%)$ \\
\hline \multicolumn{5}{|c|}{ Quem praticou o assédio moral? } \\
\hline A chefia imediata & O(a) Gestor(a) & Colegas do setor & & \\
\hline $27(40,9 \%)$ & $12(18,2 \%)$ & $27(40,9 \%)$ & & \\
\hline \multicolumn{5}{|c|}{ Qual o sexo que praticou o assédio moral? } \\
\hline Feminino & Masculino & & & \\
\hline $26(37,1 \%)$ & $44(62,9 \%)$ & & & \\
\hline \multicolumn{5}{|c|}{ Esse tipo de violência repercute na qualidade do seu trabalho e/ou em sua vida? } \\
\hline $\operatorname{Sim}$ & Não & NS/NR. & & \\
\hline $130(83,9 \%)$ & $15(9,7 \%)$ & $10(6,5 \%)$ & & \\
\hline
\end{tabular}

Fonte: dados da pesquisa.

No que tange ao público investigado, $(63,2 \%)$ afirmam nunca terem sofrido algum tipo de assédio no ambiente de trabalho. Porém, é pertinente afirmar que o assédio moral muitas vezes não é bem compreendido pelo profissional, e que o mesmo pode estar camuflado no ambiente de trabalho como uma forma de cultura e jeito como as coisas acontecem naquele espaço.

Para o público investigado, o assédio moral é cometido tanto pelas chefias como pelos próprios colegas de setor, com um percentual de $(40,9 \%)$ ambos os casos, em que o gênero que mais efetuou o assédio foi o masculino com $(62,9 \%)$ das respostas. Quanto à repercussão dessa violência, $(83,9 \%)$ afirmaram que a mesma pode influenciar na qualidade do seu trabalho e/ou em sua vida. De acordo com a afirmação anterior, os danos consequentes do assédio moral estão ligados ao âmbito da saúde física (2,3\%), no âmbito da saúde psicológico-psíquica (55,5\%), no âmbito das relações de trabalho (18,8\%), no âmbito do desempenho profissional sendo no rendimento ou produtividade (13,3\%), e nas relações de sociabilidade tanto com a 
família, como nas amizades, na afetiva (10,2\%).

O fenômeno do assédio moral quando entreposto no ambiente de trabalho possui como designo atingir diretamente a personalidade e identidade dos empregados, o que resulta na mudança de comportamento e postura do mesmo, em que a vítima acaba por afastar-se de sua realidade cotidiana, que por consequência se vê desconcentrado das suas atividades gerais, tanto no que se refere ao trabalho como também na própria vida familiar (RUI NETO, 2008).

Contudo, para aqueles que já sofreram assédio moral, (65,8\%) afirmaram não ter denunciado ou publicado uma notificação referente ao assédio e apenas (4,5\%) realizaram algum tipo de manifestação para relatar a ocorrência do assédio moral. O Quadro 2 apresenta a conduta dos respondentes ao efetuar ou não a denúncia contra o assédio moral no ambiente de trabalho, respostas oriundas das questões abertas presentes no questionário.

Quadro 2. A atitude de quem efetuou ou não as denúncias de assédio moral

\begin{tabular}{|c|c|}
\hline Caracterização & Justificativa e conduta \\
\hline \multirow{5}{*}{ Efetuaram a denúncia (22\%) } & Procura de ajuda e orientação com outras pessoas \\
\hline & A denúncia chegou até a chefia superior \\
\hline & A notificação foi aceita e repassada a empresa \\
\hline & Busca de auxílio no RH da empresa \\
\hline & $\begin{array}{l}\text { Efetuo a denúncia com intuito de coibir a ocorrência do } \\
\text { assédio moral }\end{array}$ \\
\hline \multirow{7}{*}{ Não efetuaram a denúncia (78\%) } & Medo e receio de demissão e/ou perseguição \\
\hline & $\begin{array}{l}\text { Por não acreditar que poderia ser resolvido e surtir } \\
\text { efeitos }\end{array}$ \\
\hline & Por se expor, em casos, mais que o assediador \\
\hline & Por falta de conhecimento e informação \\
\hline & Por necessidade de permanecer no trabalho \\
\hline & $\begin{array}{l}\text { Por não levar à sério o caso e caracterizar como algo } \\
\text { comum }\end{array}$ \\
\hline & Falta de coragem \\
\hline
\end{tabular}

Fonte: Dados da pesquisa.

Os resultados esclarecem a necessidade de desenvolvimento de ferramentas para neutralizar e coibir este ato de violência no ambiente de trabalho. Segundo os respondentes, ao realizar a denúncia (8,3\%) afirmaram ter recebido o acolhimento da empresa, (5\%) receberam informações quanto aos trâmites legais, $(11,7 \%)$ não receberam devida valorização. Estes indicadores demonstram que há um significativo caminho a percorrer nas empresas e que os gestores não se encontram preparados para lidar com este tipo de situação.

No que se refere aos mecanismos de enfrentamento ao assédio moral na esfera do trabalho, (62,6\%) apontaram a legislação como forma de coibir, (11,6\%) destacaram os trâmites institucionais, $(5,2 \%)$ apontaram presença do apoio sindical e $(20,6 \%)$ não souberam 
responder. Como uma forma de auxiliar e facilitar o atendimento aos(a) trabalhadores(a) em caso de assédio moral no ambiente laboral, os respondentes deram como sugestões o atendimento psicológico, ainda poder realizar denúncias por telefone com a opção de ser anônima, maior abertura para conversar com os gestores referente ao caso, possíveis denúncias nas delegacias e Ministério Público do Trabalho, o uso de ferramentas internas próprias da empresa para informar a violência.

Diante das respostas coletadas através do questionário, é possível perceber que os respondentes destacam como uma fonte eficaz as políticas de conduta e ética no meio organizacional para combater o assédio moral. A prevenção é a melhor opção no combate ao assédio moral no trabalho, a qual pode ocorrer através da promoção, da criação e do oferecimento de ações da construção sobre a prevenção deste fenômeno a todos os profissionais laborais das empresas, independente da categoria ocupada, em conjunto com folhetos informativos referentes a proibição de atos de assédio moral no local de trabalho, ainda sendo possível a criação de uma linha telefônica ou gabinete sigilosos que possam garantir o apoio necessário as vítimas (AVELINO; CONDESSO, 2016).

Defronte ao estudo realizado, e os resultados obtidos nas análises de conhecimento por meio do questionário aplicado, é relevante destacar uma pesquisa a qual foi divulgada pelo site G1 (2015) e realizar um comparativo dos dados alcançados. G1 (2015), ressalta que metade dos brasileiros já sofreu assédio no trabalho, e $(20,1 \%)$ das vítimas que efetuaram a denúncia afirmaram terem sidas demitidas e $(17,6 \%)$ alegaram ter sofrido algum tipo de perseguição. $O$ G1 ainda ressalta que em proporções semelhantes, o assédio moral ocorre com mulheres (52\%) e homens (48\%). De acordo com os dados da pesquisa (52\%) dos participantes disseram ter sofrido algum tipo de abuso, sexual ou moral, e (48\%) afirmaram não ter sofrido assédio, e do total de vítimas apenas (12,5\%) efetuaram denúncia.

Uma vez desenvolvida a análise dos dois grupos de variáveis que este estudo se propôs, o próximo capítulo apresenta as principais considerações finais, bem como as limitações e sugestões de novos estudos referentes ao tema elucidado.

\section{CONSIDERAÇÕES FINAIS}

O objetivo do presente trabalho consiste em investigar como se manifesta o assédio moral nas micro e pequenas empresas e sua ligação com o gênero. Aplicou-se uma pesquisa com 155 profissionais que atuam em micro e pequenas empresas.

Os achados sugerem que o assédio moral ocorre com ambos os gêneros tendo intensidades diferentes em determinados casos, mas as mulheres ainda são as vítimas mais assíduas e prejudicadas, por serem consideradas frágeis e vulneráveis a este tipo de violência, sendo previamente julgadas com certo teor de desigualdade no que se refere à sua capacidade 
de desenvoltura na esfera do trabalho, ainda com destaque na diferenciação de cargos e salários.

O assédio moral é reconhecido, em sua maioria, como uma violência no ambiente de trabalho que ocorre por consequência advinda da capacidade intelectual das vítimas ou ainda da indisponibilidade de trabalho em outros horários, o qual é difuso por colegas do mesmo setor ou ainda pela chefia próxima, sendo o gênero masculino o principal acometedor do assédio moral. Com grande destaque, os respondentes apontaram que a violência do assédio moral repercute na qualidade do trabalho desenvolvido e/ou na vida da vítima, em que seus principais danos estão ligados a saúde psicológico-psíquica da vítima.

O trabalho se apresenta como muito importante para todos os respondentes, levando em consideração a situação financeira para suprir suas próprias necessidades, custear as despesas familiares, bem como os compromissos de investimos imobiliários e afins, o que remete a imprescindibilidade de permanecer no trabalho. Desta forma, uma minoria da parcela de vítimas realiza algum tipo de denúncia acerca do assédio moral, isso porque os mesmos têm receio ou medo de perder o emprego, de ser perseguidos, por receber ameaças ou por falta de conhecimento e informações sobre os meios existentes para efetuar a denúncia.

No que se refere aos mecanismos de enfrentamento do ato de assédio, os respondentes apontaram a legislação, em sua maioria, como uma forma de coibir a violência no ambiente laboral, sugerindo a elaboração de ferramentas e métodos que facilite a realização das denúncias de uma forma que não expusesse os denunciantes, tanto no ambiente interno como externo das empresas, como também atividades auxiliares para o atendimento das vítimas.

Um importante ponto de reflexão é que os resultados indicam que o assédio moral acontece de forma "camuflada" no contexto das micro e pequenas empresas. Mesmo em um ambiente empresarial no qual a equipe é formada por menos pessoas, situações de humilhações, pressões emocionais e ameaças parecem fazer parte da rotina de muitos profissionais. O que sinaliza a necessidade de se ampliarem as discussões sobre este fenômeno, já que produz consequências tão fortes, a ponto de ser capaz de influenciar nos aspectos emocionais do profissional e na cultura organizacional da empresa.

Embora os objetivos deste estudo foram alcançados, é necessário destacar que existem limitações. A principal é em relação ao método, uma vez que os estudos quantitativos não são capazes de trazem os aspectos subjetivos que estão ligados ao assédio moral (contexto, cultura, gênero, região). A escolha de Micro e Pequenas Empresas também pode ser uma limitação.

Novas pesquisas podem analisar o assédio moral vinculado a outras varáveis, como: cultura organizacional, segmento de atuação e satisfação com o trabalho. Também se sugere ampliar a amostra para públicos maiores e diferentes, além de se realizarem estudos em 
organizações específicas para se preservar a homogeneidade da amostra e se melhorar a compreensão em maior profundidade do assédio moral. É relevante estudos que investiguem o posicionamento daqueles que ocupam a função de gestor, para confrontar os resultados, assim, buscar soluções que sejam efetivas para mitigar essa violência no âmbito organizacional.

\section{REFERÊNCIAS}

ALMEIDA, C.; CAVALCANTE, G.; BATISTA, H. G. Assédio no trabalho dificulta ascensão de mulheres nas empresas. O Globo, Jan. 2018. Disponível em: <

https://oglobo.globo.com/economia/assedio-no-trabalho-dificulta-ascensao-de-mulheresnas-empresas-22285265>. Acesso em: 09 de Dez. de 2018.

AVELINO, A. S. S.; CONDESSO, C. D. F. Assédio moral no trabalho: um fenômeno sombrio. Universidade Autônoma de Lisboa, 2016.

BENEVIDES, S. D.; MATOS, F. R. N.; FIGUEIREDO, N. C.; LOPES, K. L. de A. Assédio moral no trabalho: um estudo exploratório no município de Fortaleza-Ceará. Revista de Administração UFSM, Santa Maria, v.5, n.2, p 373-385, Mai./Ago.2012.

BOBROFF, M. C. C.; MARTINS, J. T. Assédio moral, ética e sofrimento no trabalho. Revista Bioética, 2013.

CAMPOS, M. I.; RUEDA, F. J. M. Assédio moral: Evidências de validade de escala e relações com qualidade de vida no trabalho. Artigo de Avaliação Psicológica da USF - Itatiba-SP, 2016.

FELIPE, J. D. L. Assédio moral contra as mulheres: um estudo com técnicas administrativas da Universidade do Estado do Rio Grande do Norte. Dissertação de Pós-Graduação em Serviços Sociais e Direitos Sociais da UERN, 2016.

FREIRE, P. A. Assédio moral e saúde mental do trabalhador. Psicologia.com.pt. 2009.

FREITAS, M. E. Assédio moral e assédio sexual: faces do poder perverso nas organizações. Revista de Administração de Empresas, São Paulo, v.41, n.2, Jan./Jun. 2001.

Quem paga a conta do assédio moral no trabalho? Revista de Administração de Empresas, Jan./Jun. 2007.

FREITAS, M. E.; HELOANI, J. R.; BARRETO, M. M. S. Assédio moral no trabalho. São Paulo: Cengage Learning; 2008.

GIL, A. C. Métodos e técnicas de pesquisa social. São Paulo: Atlas, 2008.

HIRIGOYEN, M. F. Assédio Moral: a violência perversa no cotidiano. 3a ed. Rio de Janeiro: Bertrand Brasil; 2000.

Assédio moral: a violência perversa no cotidiano. 10a ed. Rio de Janeiro: Bertrand 
Brasil; 2008.

MAÑAS, A. V. Assédio Moral nas Instituições de Ensino: definição, características e soluções. Revista Ciência da Administração, Fortaleza, v. 15, n. 2, Jul./Dez. 2009.

MARAZZO, L. M.; MEIRIÑO, M. J.; MÉXAS, M. P.; VILLELA, F. G.; DRUMOUND, G. M. Assédio moral nas organizações e seus impactos. Revista Gestão Organizacional, v.10, n.1, Jan./Abr. 2017.

MARTININGO FILHO, A.; SIQUEIRA, M. V. S. Assédio moral e gestão de pessoas: uma análise do assédio moral nas organizações e o papel da área de gestão de pessoas. Revista de Administração Mackenzie, v.9, 2008.

MENDONÇA, J. M. B.; SANTOS, M. A. F.; PAULA, K. M. Assédio moral no trabalho: estado da arte e lacunas de estudos. Gestão \& Regionalidade, v.34, n.100, Jan./Abr. 2018.

RIBEIRO, C. R. B.; MANCINI NETO, P. Assédio moral: o poder perverso nas empresas. Revista Pretexto, Belo Horizonte, Jul. 2003.

RICHARDSON, R. J. Pesquisa Social: Métodos e Técnicas. São Paulo: Atlas, 2011.

RUI NETO, A. Assédio Moral contra Mulher nas Relações de Trabalho: uma reflexão sobre suas consequências econômicas e psicológicas. Universidade Federal de Mato Grosso do Sul, 2008.

SILVA, L. P.; CASTRO, M. A. R.; DOS-SANTOS, M. G. Influência da Cultura Organizacional Mediada pelo Assédio Moral na Satisfação no Trabalho. RAC - Revista de Administração Contemporânea, Rio de Janeiro, v.22, n.2, Mar./Abr. 2018.

SILVA, V. V.; NAKATA, L. E. Da deterioração das relações à escolha pela permanência: O assédio moral no trabalho. Recape Revista de Carreiras e Pessoas, São Paulo, v.6, n.2, Mai./Jun./Jul./Ago. 2016.

SCHERE, M. D. A.; PIRES, D.; SCHWARTZ, Y. Trabalho coletivo: um desafio para a gestão em saúde. Revista de Saúde Pública, São Paulo, SP, v.43, n.4, 2009.

SOARES, L. Q. Interações socioprofissionais e assédio moral no trabalho: "ou você interage do jeito deles ou vai ser humilhado até não aguentar mais". São Paulo: Casa do Psicólogo, 2008.

TARCITANO, J. S. C.; GUIMARÃES, C. D. Assédio moral no ambiente de trabalho. Centro de Educação Tecnológica Estácio de Sá de Juiz de Fora, 2004.

TEIXEIRA, R. F.; REIS, M. C.; SANTOS, L. M. L. Assédio moral no trabalho: um estudo sobre as práticas de prevenção e combate ao fenômeno em empresas do norte do Paraná. Revista de Administração UFSM, Santa Maria, RS, v.6, n. 4, Dez. 2013.

VALADÃO JUNIOR, V. M.; MENDONÇA, J. M. B. Assédio moral no trabalho: dilacerando oportunidades. Cadernos Ebape.BR, Rio de Janeiro, v.13, n.1, Jan./Mar. 2015. 
VASCONCELOS, Y. L. Assédio moral nos ambientes corporativos. Cadernos Ebape.BR, Rio de Janeiro, v.13, n.4, Out./Dez. 2015.

VENTURA, E. F.; TEIXEIRA, L. A. A.; OLIVEIRA, R. R.; PORTO, L. Assédio moral e seu dano na saúde mental dos indivíduos. Revista de Administração e Inovação Hospitalar, Belo Horizonte - MG, v.14, n.4, Out./Dez. 2017. 